\title{
Nuclear Reactors: Physics and Materials
}

\author{
George Yadigaroglu*
}

\begin{abstract}
In the form of a tutorial addressed to non-specialists, the article provides an introduction to nuclear reactor technology and more specifically to Light Water Reactors (LWR); it also shows where materials and chemistry problems are encountered in reactor technology. The basics of reactor physics are reviewed, as well as the various strategies in reactor design and the corresponding choices of materials (fuel, coolant, structural materials, etc.). A brief description of the various types of commercial power reactors follows. The design of LWRs is discussed in greater detail; the properties of light water as coolant and moderator are put in perspective. The physicochemical and metallurgical properties of the materials impose thermal limits that determine the performance and the maximum power a reactor can deliver.
\end{abstract}

Keywords: Light water $\cdot$ Reactor physics $\cdot$ Reactor technology $\cdot$ Thermal limits $\cdot$ Tutorial

\section{Introduction}

This article is intended to provide an introduction to nuclear reactor technology, and more specifically Light Water Reactor (LWR) technology, for readers interested in "Chemistry and Materials in Nuclear Power Production" covered in depth in this special issue. It is a tutorial addressed to the nonspecialist and also attempts to show where materials and material chemistry problems show up in reactor technology.

Starting from the fundamentals of fission, we review briefly the various options available to the nuclear engineer for designing a power reactor, the choice of design strategies, with emphasis on materials and coolants available, and show how different combinations lead to different reactor types. We then list the various types of reactors that have reached commercial status and finally concentrate on the design of Light Water Reactors (LWR) that constitute today the great majority of commercial power plants.

${ }^{*}$ Correspondence: Prof. G. Yadigaroglu, em.

ETH, WEN B13

Weinbergstrasse 94

$\mathrm{CH}-8006$ Zurich

Tel.: +41446324615

Fax: + 41446321105

E-Mail: yadi@ethz.ch
All nuclear reactors have a central 'core', the space filled with nuclear fuel and other materials where the fission take place. Nuclear heat is created by fissions in the core and must be extracted and used. For this purpose, a large number of components and systems surround the core. The choice of materials depends on their nuclear as well as physicochemical properties and their compatibility with each other under operating conditions. The materials are kept under acceptable operating conditions by a number of auxiliary systems, such as the coolant conditioning system that maintains appropriate chemistry in the coolant. Numerous safety systems are provided to protect the core and mitigate incidents and accidents [1]. Although the basic principle, the design, and the configuration of a nuclear reactor are very simple, materials and chemistry problems create a number of concerns that must be addressed for successful and safe operation.

\section{Reactor Physics}

\subsection{Fission}

A free neutron hitting a heavy nucleus like U-235 may split it mainly into two fragments, the 'fission products', release a number of 'fission neutrons' and, most important, energy. There are several characteristics of this nuclear reaction that make it particularly attractive for producing energy and one that unfortunately creates safety issues.

A large amount of energy is released per atom fissioned, roughly $200 \mathrm{MeV}$, while chemical reactions release amounts in the order of $\mathrm{eV}$ and most other nuclear reactions, including fusion reactions, amounts of the order of 1-10 MeV. Most of this energy is deposited in the nuclear fuel in the core and is easily extractable.

More than one fission neutron is produced per fission, 2.5 to 3.5 on average, depending on the energy of the neutron that produced the fission and the fissioning isotope. This makes a steady chain reaction possible without a source of external neutrons. In a nuclear reactor, one of the fission neutrons is needed to keep the chain reaction going and the reactor 'critical', i.e. at a steady state: in a critical reactor the neutron production rate matches the neutron loss rate. The excess 1.5 to 2.5 neutrons will leak out of the reactor core or be absorbed in the fuel or other core materials without producing fission. Some of these excess neutrons can, however, be used in a very interesting way, as we will see below.

A small fraction $(\sim 0.5 \%)$ of the fission neutrons are not 'prompt, i.e. are not produced during the fission process, but rather by the decay of certain radioactive fission products. These 'delayed neutrons' appear seconds to minutes later and also contribute to the chain reaction and to the neutron balance that keeps the reactor critical. However, they introduce a welcome lag in the kinetics of the reactor that makes criticality control much easier.

The unfortunate fact is that typically two, generally radioactive, fission products are created by each fission. The unavoidable radioactive fission products have half lives ranging from seconds or less (these are very radioactive but, obviously, do not survive very long) to millions of years (these are 
by nature less radioactive, but very longliving).

The radioactive fission products must not be released to the environment during any phase of the fuel cycle - this is the central concern of reactor and nuclear safety. During normal reactor operation, the fission products are confined within the fuel and one has to worry only about relatively small leaks from there [2]. There are, however, some other sources of radioactivity accumulation and potential release from a reactor, e.g. the products of neutron activation of reactor components and of the coolant; again interesting materials and materials interaction issues appear.

Reactor accidents result from an imbalance of energy generation and extraction from the reactor core; in both cases there is the possibility of overheating and damaging the fuel, leading to fission product release from the large inventory accumulated during reactor operation in the core. During an accident, the fuel and other materials in the core may be exposed to very broad ranges of temperatures and pressures; understanding material behaviour and materials interactions under accidental conditions is an ever greater challenge, see $e . g$. [3].

\subsection{Criticality}

To understand the various options available in designing different types of reactors, in relation to the materials used, we should recall first some basic facts:

As already mentioned, to obtain a sustainable nuclear chain reaction, we must achieve a steady neutron balance or criticality, i.e. conditions under which the average number of neutrons emitted per fission equals the number of neutrons:

- absorbed in the fuel,

- absorbed elsewhere in the core,

- leaking out of the core.

In small cores, the ratio between the surface of the core from where neutrons leak out and the volume of the core where they are created is large and neutron leakage and loss from the core is too large to achieve criticality. A sufficient amount of nuclear materials must be assembled to create a large enough core volume or critical mass, i.e. a critical system where a nuclear chain reaction is self-sustained. Alternatively, by modifying the proportions of the fissionable and other materials in a reactor core of a given volume, one influences the rates at which neutrons are created by fission or absorbed; this is the second way of achieving criticality. Thus, the proper combination of nuclear materials must be chosen to achieve criticality. The combination of materials chosen determines the type of reactor.

\subsection{Nuclear Fuels}

Natural uranium, the main source for nuclear fuel, consists of $99.27 \%$ U-238 and $0.72 \% \mathrm{U}-235$ (there is also $0.0057 \%$ $\mathrm{U}-234)$.

A neutron must have a kinetic energy of at least $1 \mathrm{MeV}$ to cause fission of a U238 nucleus (U-238 is fissionable). In contrast, neutrons of any energy and especially neutrons of very low energy (the so-called thermal neutrons, because they are in thermal equilibrium with their environment) can cause fission of a U-235 nucleus (U235 is for this reason called fissile; U-238 is fissionable but not fissile). There are three fissile isotopes of practical interest: U-235, $\mathrm{Pu}-239$ and $\mathrm{U}-233$. The first one is an isotope of natural uranium; the other two are produced in nuclear reactors (Fig. 1).

For fissile materials (like U-235) the probability of fission (the 'fission crosssection') is very large ( 500 barn (1 barn $=10^{-24} \mathrm{~cm}^{2}$ ) and increases as the energy of the fission producing neutron decreases. For the fissionable but not fissile materials (like U-238) the fission cross-section is much smaller ( 1 barn) and it is zero below a certain threshold neutron energy.

The fission neutrons that are produced by splitting the atom are born with energies of the order of the MeV. These energies are not optimal for producing fission in fissile materials like U-235. To take advantage of the fact that the fission cross-section of fissile nuclei increases as the energy of the neutron decreases, one slows down the neutrons by collisions with light nuclei (like H, D, C, etc.). Collisions with light nuclei (that have a mass not that different from the mass of a neutron) are most efficient in rapidly slowing down the neutrons, so that the chance of their being absorbed in materials other than the fuel (as they are slowing down) is minimized. Materials containing such light nuclei are called moderators.

The fissionable U-238 can absorb a neutron and, after a chain of transformations or decays, produce fissile $\mathrm{Pu}-239$; for this reason it is called fertile. Thorium-232 is the second fertile material; it produces fissile $\mathrm{U}-233$. Fissile $\mathrm{Pu}-239$ is also produced in nuclear reactors, starting from U-238 (Fig. 1).

Conversion of fertile material into fissile can always take place in a reactor; all reactors are converters of fertile into fissile material. If the number of fissile nuclei produced per fissile nucleus consumed (fissioned or lost due to neutron absorption)

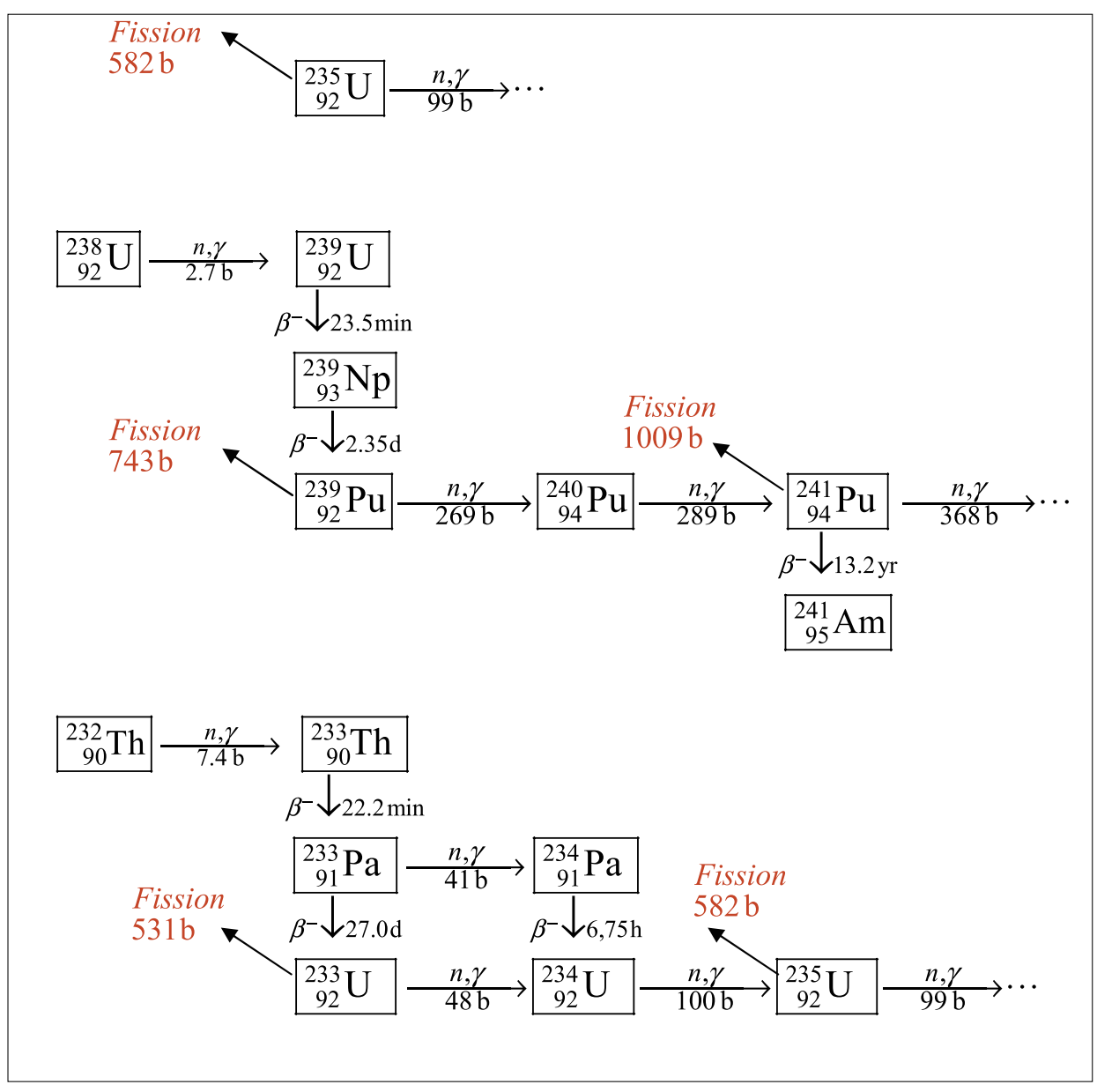

Fig. 1. Simplified presentation of the nuclear reactions in uranium and thorium fuelled reactors. The blue and green boxes indicate fissile and fertile isotopes, respectively. The $(n, \gamma)$ reactions denote absorption of the neutron in the heavy nucleus. The cross-sections are given in barn (b), as well as the modes of radioactive $\beta$ decay and the corresponding half-lives. 
exceeds one, the converter is a breeder. A breeder produces more fissile fuel than it consumes.

\subsection{Thermal Reactors versus Fast Breeders}

One option available to the reactor designer is to use a moderating material in the core in order to slow the neutrons down to thermal energies, where they can be much more efficient in producing fission; we have in this case a thermal reactor. In such reactors the neutrons slow down from the energies they have at birth $(\sim 1 \mathrm{MeV})$ and come close to thermal equilibrium with their environment: at $20{ }^{\circ} \mathrm{C}$, they have a most probable kinetic energy of $0.0253 \mathrm{eV}$. Many materials have appreciable absorption cross-sections for thermal neutrons; if they are present in the core they will absorb neutrons and remove them from the neutron balance. Consequently, in a thermal reactor, we are restricted in the choice of materials, if we wish to achieve good neutron economy.

In a fast reactor, we avoid slowing down the neutrons to thermal energies and take advantage of the fact that fissions produced by high-energy neutrons generate a larger number of neutrons (maybe 3.5 instead of 2.5 per fission). In such a reactor, we must not use any light material (for example coolant) that will slow down the neutrons. In a fast reactor, there is a sufficiently high number of 'excess' neutrons; these can be used to convert fertile fuel materials (such as U-238) into fissile ones (such as $\mathrm{Pu}$-239). Thus, fast reactors are usually designed as breeders. The fact that most of the neutron absorption cross-sections of core materials become much smaller as the energy of the neutrons increases opens new possibilities for the use of structural materials and coolants.

\subsection{Power Distribution in the Core}

One of the main problems of reactor physics is to compute the free neutron density distribution in the core of the reactor and the resulting fission rate distribution that is directly proportional to the local nuclear heat source in the fuel. Indeed, most of the energy liberated by fission is deposited in the near vicinity of the fissioning nucleus, i.e. in the fuel itself, a few percent further away in the cladding or the coolant.

In principle, a nuclear reactor can be operated at any power level. In reality, the materials used in the core, fuel, cladding, structural materials, and coolant impose limitations, the so-called thermal limits. The thermal limits will be discussed in more detail and in relation to LWRs below.

Elementary methods of reactor physics such as the diffusion theory of neutrons provide the power distribution for very simple cases, like a core having a very simple geometry, e.g. a cylinder homogeneously loaded with fuel. According to these simple solutions, the shape of the power distribution of the core is a cosine or a function similar to a cosine in each coordinate direction. The power peaks at the centre of the core and is near zero at the boundaries of the core. In reality, the cores of power reactors are not uniformly loaded with fuel, the local isotopic composition of the core changes as the fuel burns and fission products accumulate, the coolant distribution and properties change in time, control materials are inserted in a non-uniform way etc. The power distribution in a real reactor is much more complex. Fig. 2 shows an example of power distribution in a BWR core; the power distribution is particularly complex in Boiling Water Reactors (BWRs) where the core is more inhomogeneous compared to a Pressurized Water Reactor (PWR). The issues raised by the non-uniform power distribution in the core will be discussed in the section on Thermal Limits below.

\section{Reactor Design and Engineering}

The core of a nuclear reactor contains the nuclear fuel in various forms, the moderating materials, if any, and the coolant. The fuel must typically be supported by some structural material. Some neutron-absorbing control material must be inserted in a controlled way into the core to make it and keep it critical. There is a choice of ma- terials for each of these functions; the most common ones are listed in Table 1.

Additionally, around the core we may find:

- a reflector to minimize loss of neutrons by leakage; outward directed neutrons collide with reflector nuclei and have a chance of returning back to the core;

- a breeding blanket made of fertile material (in the case of fast reactors) where conversion of fertile into fissile fuel takes place;

- a thermal shield, generally made of steel, to protect the reactor vessel from neutrons and/or high temperatures;

- the reactor vessel containing the nuclear part of the system and parts of the cooling system; if the reactor coolant is under pressure, this is the Reactor Pressure Vessel (RPV);

- a thick biological shield, made of concrete, steel, lead, etc. that protects the personnel and equipment from radiation coming from the core.

\subsection{The Fuel}

In most power reactors, the fuel is in the form of small cylindrical pellets (diameter and height $\sim 1 \mathrm{~cm}$ ) inserted into long metallic cladding tubes a few meters long: the resulting fuel rods or fuel pins are surrounded by coolant and (in thermal reactors) moderating material. The fuel rods are assembled together in fuel bundles in square or hexagonal lattices. The rods are held together

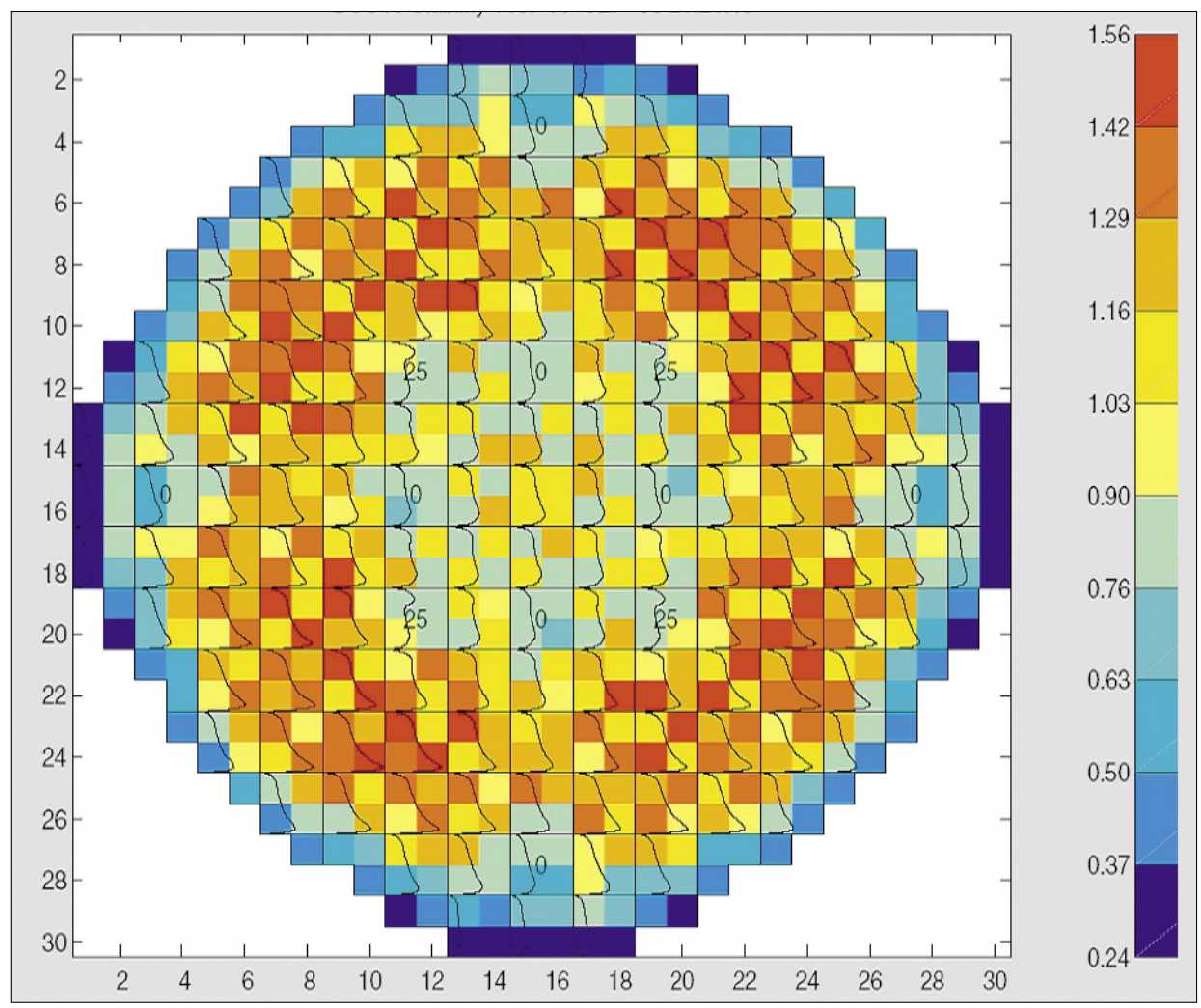

Fig. 2. Power distribution in the core of a BWR. The colour indicates the average relative bundle power, while the small graphs in the figure show the axial power distribution at that location in the core (Computations by B. Askari, ETHZ). 
Table 1. Choice of Nuclear Materials ${ }^{a}$

\begin{tabular}{|c|c|c|c|c|}
\hline Fuel & Moderator & Coolant & $\begin{array}{l}\text { Cladding and } \\
\text { structural } \\
\text { materials }\end{array}$ & $\begin{array}{l}\text { Control } \\
\text { materials }\end{array}$ \\
\hline $\begin{array}{l}\text { Natural U metal } \\
\text { Slightly enriched } \mathrm{UO}_{2} \\
\mathbf{( 2 - 5 \% )} \\
\text { U alloys } \\
\text { Medium or highly enriched } \\
\text { U or Pu metal, oxides, } \\
\text { carbides } \\
\text { etc. } \\
\text { Fertile materials: } \\
\text { U-238, Th-232 }\end{array}$ & $\begin{array}{l}\mathrm{H}_{2} \mathrm{O} \\
\mathbf{D}_{2} \mathrm{O} \\
\text { Graphite } \\
\mathrm{BeO}, \mathrm{Be} \\
\text { Organics } \\
\mathrm{LiH} \\
\text { etc. }\end{array}$ & $\begin{array}{l}\text { He } \\
\text { Steam } \\
\text { Organic } \\
\text { coolants } \\
\text { Liquid me- } \\
\text { tals: } \mathrm{Na}, \mathrm{NaK} \text {, } \\
\mathrm{Pb} \text {, etc. }\end{array}$ & $\begin{array}{l}\text { Al (for low tempera- } \\
\text { ture water) } \\
\text { Stainless-steel } \\
\text { (for } \mathrm{Na} \text { and high } \\
\text { temperature water) } \\
\mathrm{Zr} \text {, zircaloy (for } \\
\text { high temperature } \\
\text { water) } \\
\text { Graphite (for gases) } \\
\text { etc. }\end{array}$ & $\begin{array}{l}\mathrm{B}-10 \\
\mathrm{~B}_{4} \mathrm{C} \\
\mathrm{Hf} \\
\mathrm{Gd} \\
\text { In } \\
\mathrm{Ag}-\mathrm{In}-\mathrm{Cd} \\
\text { etc. }\end{array}$ \\
\hline
\end{tabular}

by spacers and bundle top and bottom hardware in the fuel bundles; occasionally the entire bundle is surrounded by a box.

Other fuel arrangements are, however, possible; $e . g$. in certain gas cooled reactors, the fuel is in the form of (sub-)millimetresized fuel particles, coated with several layers of graphite and silicon carbide. These particles, mixed with additional graphite, form then fuel spheres (typically $50 \mathrm{~mm}$ in diameter).

\subsection{Reactor Coolants and Energy Conversion}

In a reactor built to produce energy (heat) a coolant is usually circulated through the core to extract the nuclear heat. Obviously, a good coolant must:
- be suitable from the heat transfer point of view so that the fuel temperatures stay low;

- have acceptable nuclear properties in relation to neutron absorption and moderation;

- be compatible with the structural materials present in the reactor;

- be acceptable as working fluid or heat transfer medium at the energy-receiving end of the heat transfer loop.

Usual coolants are: air, helium, carbon dioxide, ordinary and heavy water, sodium, a mixture of sodium and potassium $(\mathrm{NaK})$ etc. Table 2 compares their properties.

\section{Current Commercial Reactors}

After the brief introduction of the previous sections, we will see how the combination of the various core materials shown in Table 1 determines the type of reactor. The discussion is limited to commercial power reactors for electricity production [4]. Their main characteristics are compiled annually in [5].

A very large number of reactor designs have been proposed or tested starting in the 1950s. The main types of reactors which for technical, economic, political and other reasons have 'survived' the competition and exist today in significant numbers around the world are briefly mentioned now:

Table 2. Reactor Coolants and their relevant properties

\begin{tabular}{|c|c|c|c|}
\hline & $\begin{array}{l}\text { Light Water (and } \\
\text { to some extent heavy-water) } \\
\text { PWR BWR }\end{array}$ & Liquid Metals & $\begin{array}{l}\text { Gases } \\
\text { e.g. } \mathrm{CO}_{2} \text {, } \mathrm{He}\end{array}$ \\
\hline $\begin{array}{l}\text { Moderating } \\
\text { characteristics }\end{array}$ & $\begin{array}{l}\text { excellent } \quad \text { very good } \\
\rightarrow \text { thermal reactors }\end{array}$ & $\begin{array}{l}\text { poor } \\
\rightarrow \text { fast reactor in the absence of } \\
\text { other moderators, e.g. graphite }\end{array}$ & $\begin{array}{l}\text { poor } \\
\rightarrow \text { fast reactor in the absence of } \\
\text { other moderators, e.g. graphite }\end{array}$ \\
\hline $\begin{array}{l}\text { Heat transfer } \\
\text { characteristics }\end{array}$ & $\begin{array}{l}\text { very good } \\
\text { limited by critical heat flux (CHF) }\end{array}$ & excellent & $\begin{array}{l}\text { poor at low pressure, improves with } \\
\text { pressure and using extended sur- } \\
\text { faces }\end{array}$ \\
\hline System pressure [bar] & $150-155$ & atmospheric or slightly above & $10-48$ \\
\hline Material problems & corrosive at high temperature & $\begin{array}{l}\text { corrosive; } \mathrm{Na}_{2} \mathrm{O} \text { precipitation; } \\
\text { plugging }\end{array}$ & $\begin{array}{l}\text { no corrosion effects, some } \\
\text { material transport with } \mathrm{CO}_{2}\end{array}$ \\
\hline $\begin{array}{l}\text { Coolant stability and } \\
\text { activation }\end{array}$ & $\begin{array}{l}\text { small radiolytic effects, small } \\
\text { induced radioactivity ( }{ }^{16} \mathrm{~N} \text { in the } \\
\text { steam of BWRs) }\end{array}$ & high activation ( ${ }^{24} \mathrm{Na}$ production) & no activation if pure \\
\hline Handling of coolant & $\begin{array}{l}\text { safe to handle (except when } \\
\text { pressurized), transparent (easy } \\
\text { refueling) } \\
D_{2} \mathrm{O} \text { leaks expensive }\end{array}$ & $\begin{array}{l}\text { flammable; reacts violently with } \\
\text { water; not transparent; solidifies at } \\
\text { room temperature (trace heating } \\
\text { needed) }\end{array}$ & $\begin{array}{l}\text { (with } \mathrm{He} \text { ) losses by leaks from the } \\
\text { system can be a problem }\end{array}$ \\
\hline Other characteristics & $\begin{array}{l}\text { abundant, inexpensive; } \\
\text { need for pressurization } \\
\rightarrow \text { flashing during LOCA }\end{array}$ & $\begin{array}{l}\text { high boiling temperature, } \\
\text { very high thermal conductivity }\end{array}$ & pumping costs high \\
\hline
\end{tabular}


The Light Water Reactors (LWR) can be either Pressurized Water Reactors (PWR) or Boiling Water Reactors (BWR). Their cores have the following composition:

- Fuel: uranium dioxide slightly (3-5\%) enriched in the fissile isotope U-235 or 'Mixed Oxides' (MOX), i.e. a mixture of uranium dioxide and recycled plutonium dioxide that partly replaces U-235 as the fissile material [6];

- Coolant and moderator: ordinary ('light') water;

- Cladding and structural materials: mostly Zircaloy (an alloy of zirconium - a material with low neutron absorption cross section), in early concepts also stainless steel;

- The core is placed in a large RPV.

LWR designs and their thermal-hydraulic characteristics are described in more detail below. One should add to the LWR list the Russian VVER pressurized water reactors.

Most of the heavy water reactors are Canadian-type CANDU reactors (CANadian Deuterium, natural-Uranium). Their fuel and structural materials are similar to those of the LWRs, but heavy water is used as moderator and coolant. The fuel is not necessarily enriched. There is no reactor pressure vessel; a large number of fuel bundles and coolant channels are enclosed in horizontal pressure tubes traversing a large vessel (the 'calandria') containing heavy water moderator. The pressure-tube design makes on-line refuelling possible.

Gas-Cooled Reactors (GCR) There are several generations of these: Magnox, Advanced Gas Cooled Reactor (AGR), HighTemperature Gas-Cooled Reactor(HTGR), Hochtemperatur Reaktor (HTR), and more recent designs like the Modular High-Temperature Gas-cooled Reactor, MHTGR. These employ:

- Fuel: either metallic or oxide fuels for the old designs, coated, mixed-oxide particles embedded in a graphite matrix for the most recent ones;

- Moderator and structural material: graphite;

- Coolant: carbon dioxide in old designs and helium in all recent designs.

In the US developments, the HTGR fuel is embedded in hexagonal graphite blocks with cooling channels. In Germany the fuel had the form of randomly piled $6 \mathrm{~cm}$ spheres coated with graphite.

The Liquid Metal cooled Fast Breeder Reactor (LMFBR) is the option that has been developed most. Its design features

- Fuel: mixed oxides of uranium and plutonium;

- Moderator: none;

- Cladding and structural material: stainless steel;

- Coolant: liquid sodium.
The primary system is either completely immersed in a very large vessel (pool type) or has (double wall) piping (loop type). An intermediate liquid metal circuit transfers the heat from the primary sodium loop to the steam/water circuit that produces the power.

Various new reactor concepts are at different R\&D and design phases today. In the so-called 'evolutionary' (sometimes called 'third generation-plus') plants, the basic design and the mode of operation under normal conditions have not changed much, but additional emphasis has been put on further improving safety systems and on their safety performance. One way of achieving enhanced safety performance while keeping plant design as simple as possible, has been the replacement of active emergency core and containment cooling systems with passive ones [7]. A number of passive plants have been designed around the world.

A systematic effort started recently in the USA and then spread internationally (focusing on so-called 'fourth generation' concepts), to design the nuclear power systems of the future considering all aspects of the problem, i.e. sustainability, safety and reliability, and economics. Several plant types were selected and international research needs related to these so-called Generation IV plants have been defined [8] Some of these plants have rather futuristic or exotic features, coolants, fuels, etc. They will certainly produce a plethora of interesting chemistry and materials problems.

\section{Light Water Reactors}

The majority of the existing power reactors today are Light Water Reactors (LWR). They also constitute the majority of reactors in the planning or construction phase. LWR types such as the VVERs that have been developed and are in use in eastern countries are not discussed here. As noted above, LWRs in the western world exist as either Pressurized Water Reactors (PWR) or Boiling Water Reactors (BWR).

\subsection{Basic Design}

The present PWR designs of US, as well as European and Asian vendors were all derived from the original Westinghouse design and still bear strong similarities among themselves, in spite of divergences in later improvements. The same is true for the BWRs, which were initially developed by the General Electric Company and later under license by other manufacturers. Fig. 3 shows a typical PWR vessel and its internals.

In the PWRs, the coolant circulates in two to four loops, according to the reactor power; see e.g. [9]. The primary system is pressurized typically to 155 bar and there is no net steam production in the core. The

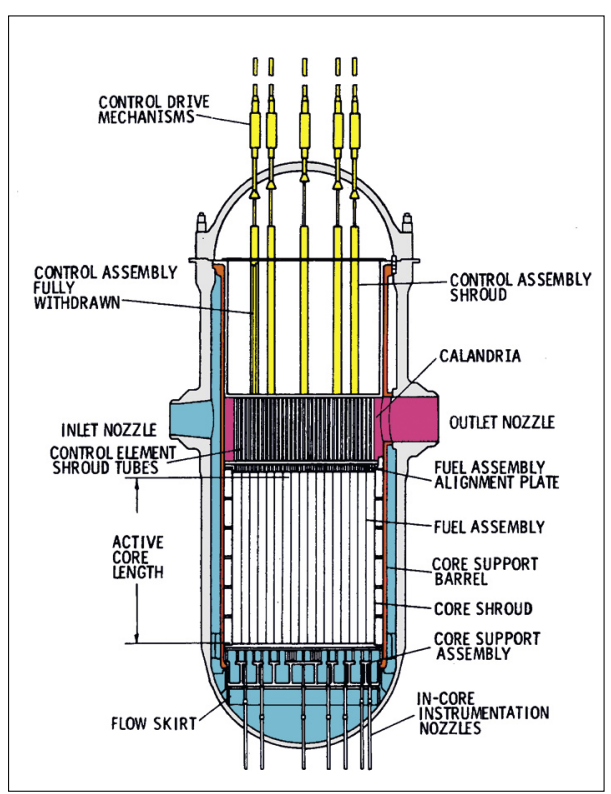

Fig. 3. Schematic representation of a typical PWR vessel.

coolant exits the RPV with a subcooling of $\sim 20-30{ }^{\circ} \mathrm{C}$. It passes then in the U-tubes of a Steam Generator (SG) where it transfers heat to the secondary boiling side, which is at a lower pressure, typically around 70 bar. It is then pumped back into the vessel. Obviously, the secondary side of the SG must be at a lower saturation temperature (and consequently pressure) so that there is a driving temperature difference for heat exchange between the primary and the secondary sides of the SG. The steam from the SG is fed to the turbine [9].

In the direct-cycle BWR (Fig. 4) the coolant is at a pressure around 70 bar and is allowed to boil in the core. The saturated steam that is produced is directly fed to the turbine; see e.g. [10]. There is internal recirculation in the BWR vessel that can be driven in several ways. In most US designs, jet pumps located in the periphery of the RPV and driven by external recirculation pumps produce the internal circulation. The advantage of jet pumps is the absence of moving parts inside the RPV. In European and the most recent BWR designs, the jet pumps are replaced by internal cannedmotor impellers; the external recirculation pumps and the corresponding piping are eliminated. Some past and future designs rely on natural circulation inside the vessel, promoted by a tall riser above the core. The quality of the steam-water mixture exiting the core (i.e. the fraction of the total mass flow rate that is steam) is about $15 \%$. The steam is separated from the recirculating water by steam-water separators, dried in the upper plenum of the vessel, and directed to the turbine-generator [10].

In both PWRs and BWRs, the steam delivered to the turbine is at about the same conditions, namely saturated at 70 bar and $285.8{ }^{\circ} \mathrm{C}$. Table 3 compares the character- 


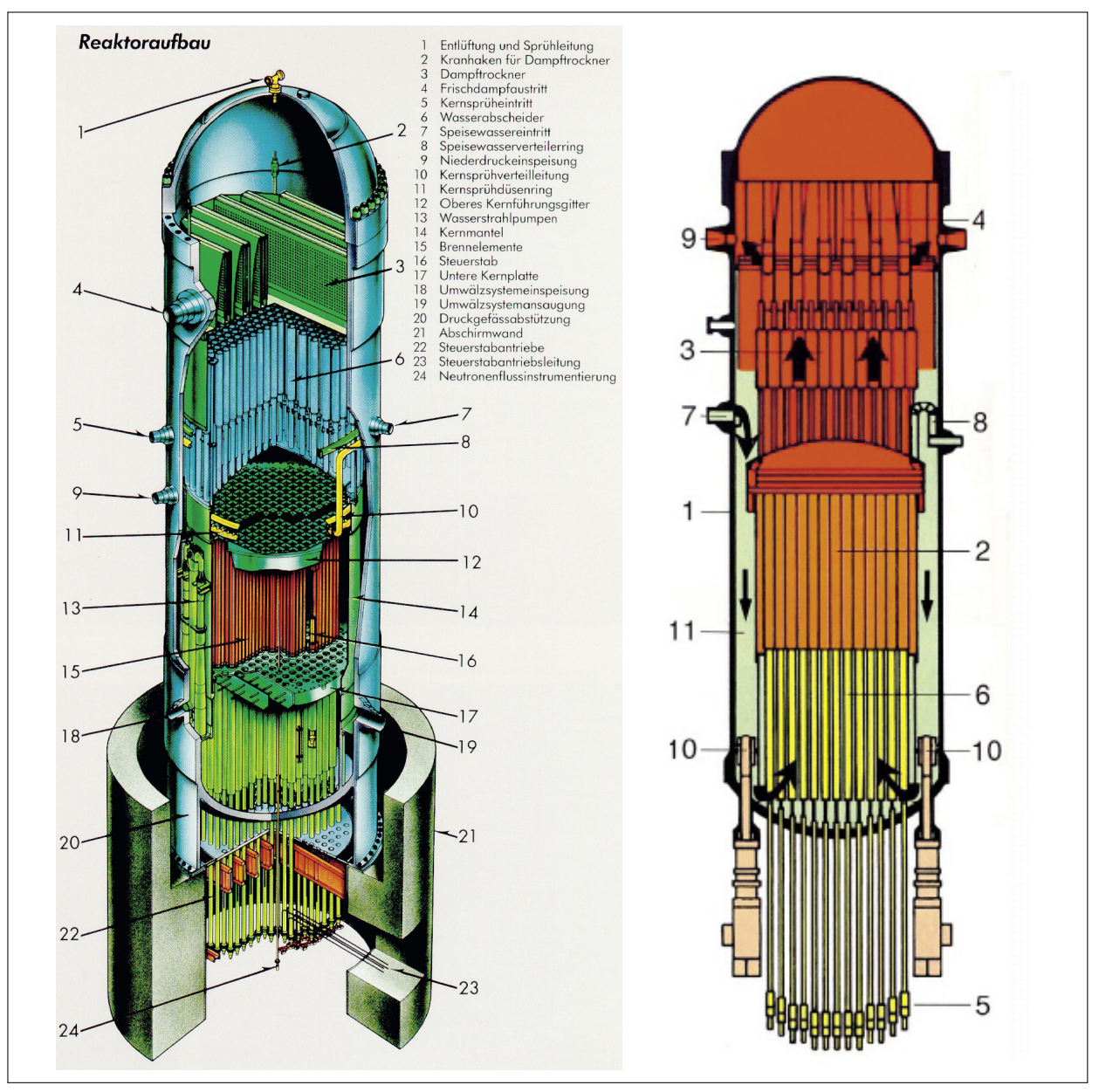

Table 3. Operational parameters for 1200 MWe PWR and BWR (typical operating reactors)

\begin{tabular}{|c|c|c|c|}
\hline & & PWR & BWR \\
\hline Thermal power rating & MWth & 3750 & 3840 \\
\hline Electrical power output & MWe & 1240 & 1249 \\
\hline Thermodynamic efficiency & $\%$ & 33 & 32.5 \\
\hline Reactor coolant flow & $\mathrm{kg} / \mathrm{s}$ & 20000 & 14300 \\
\hline Coolant pressure at core exit & bar & $145-155$ & $70-72$ \\
\hline Steam flow to turbine & $\mathrm{kg} / \mathrm{s}$ & 1990 & 1940 \\
\hline Steam pressure at turbine inlet & bar & $52-72$ & $67-70$ \\
\hline Steam temperature at turbine inlet & ${ }^{\circ} \mathrm{C}$ & $266-284$ & $282-285$ \\
\hline Feedwater temperature & ${ }^{\circ} \mathrm{C}$ & 210-226 & 215 \\
\hline \multicolumn{4}{|l|}{ Reactor core ${ }^{a}$} \\
\hline Average heat flux ${ }^{a}$ & $\mathrm{~kW} / \mathrm{m}^{2}$ & 610 & 505 \\
\hline Specific fuel power & $\mathrm{kW} / \mathrm{kgU}$ & 36.7 & 26 \\
\hline Average power density & $\mathrm{kW} / \mathrm{l}$ & 92.3 & 56 \\
\hline Average fuel linear power & $\mathrm{kW} / \mathrm{m}$ & $18-20$ & $13-21$ \\
\hline Number of fuel bundles & & 193 & 784 \\
\hline Fuel rods per bundle a & & $176-324$ & $64-96$ \\
\hline Active fuel rod length & $\mathrm{mm}$ & $3700-4400$ & $3600-4000$ \\
\hline Fuel rod outside diameter ${ }^{a}$ & $\mathrm{~mm}$ & $9.3-12$ & $9.6-12.5$ \\
\hline \multicolumn{4}{|l|}{ Reactor Pressure Vessel } \\
\hline Inner diameter & $\mathrm{m}$ & 5.0 & 6.6 \\
\hline Wall thickness & $\mathrm{mm}$ & $217-243$ & 163 \\
\hline Total height & $\mathrm{m}$ & 13 & 23 \\
\hline Weight & $\mathrm{t}$ & 530 & 785 \\
\hline
\end{tabular}

Fig. 4. BWR reactor pressure vessels. Typical US design with jet pumps on the left and German design with internal impellers on the right. Left figure: 1 Vent and head spray. 2 Steam dryer lifting lug. 3 Steam dryer. 4 Steam outlet. 5 Core spray nozzle. 6 Separators. 7 Feedwater nozzle. 8 Feedwater sparger. 9 Low-pressure coolant injection. 10 Core spray line. 11 Spray nozzle sparger ring. 12 Top guide. 13 Jet pumps. 14 Core shroud. 15 Fuel assemblies. 16 Control blade. 17 Lower core plate. 18 Jet pump recirculation inlet. 19 Jet pump recirculation outlet. 20 Vessel support skirt. 21 Shield wall. 22 Control rod drive. 23 Control rod drive hydraulic lines. 24 In core flux monitor. Right figure: 1 Reactor pressure vessel. 2 Core. 3 Separators. 4 Dryers. 5 Control rod drives. 6. Control rods. 7 Feedwater inlet. 8 Coolant injection. 9 Steam outlet. 10 Internal recirculation impeller.

istics of the two systems. Fig. 5, where the relation between saturation pressure and temperature for ordinary (or 'light') water is plotted, shows the operating points of the two systems and illustrates the fact that although the PWR operates at a higher pressure, because of the need to transfer heat to the working fluid in a SG, the power generating cycles operate between practically identical points.

The pressure in the vessel of a BWR is maintained at the desired level by adjusting the flow of steam to the turbine and the power production level. The steam dome at the top of the RPV acts as a pressuriser. The PWR primary system is filled 'solid', i.e. there is no free surface within the RPV. Thus, one needs an external pressuriser to allow for expansion of the primary system coolant and reduce variations of primary pressure.

Reactivity control in LWRs is achieved through movable control rods, poisons dissolved in the coolant (chemical shim), by adjusting the thermal-hydraulic conditions of the core in BWRs (modifying the recirculation ratio to change the void fraction of the core), and by burnable poisons incorporated in the fuel rods (mechanical shim). The chemical shim is obtained by adding or extracting boric acid via the reactor coolant Chemical and Volume Control System to the coolant, the complex system that controls the 
chemistry of the coolant and the coolant inventory in the primary system of PWRS.

\subsection{PWR Steam Generators}

PWR Steam Generators are large pieces of equipment and crucial to the good operation of the system. Moreover, they present a number of challenging materials and coolant chemistry problems.
Although it is in principle possible to slightly superheat the steam in the steam generator of a PWR (theoretically up to the exit temperature from the primary system), this was done only by one vendor $(\mathrm{B} \& \mathrm{~W})$ who used a once-through steam generator allowing superheating of the secondary-side steam. This approach was abandoned. Fig. 6 shows schematically a

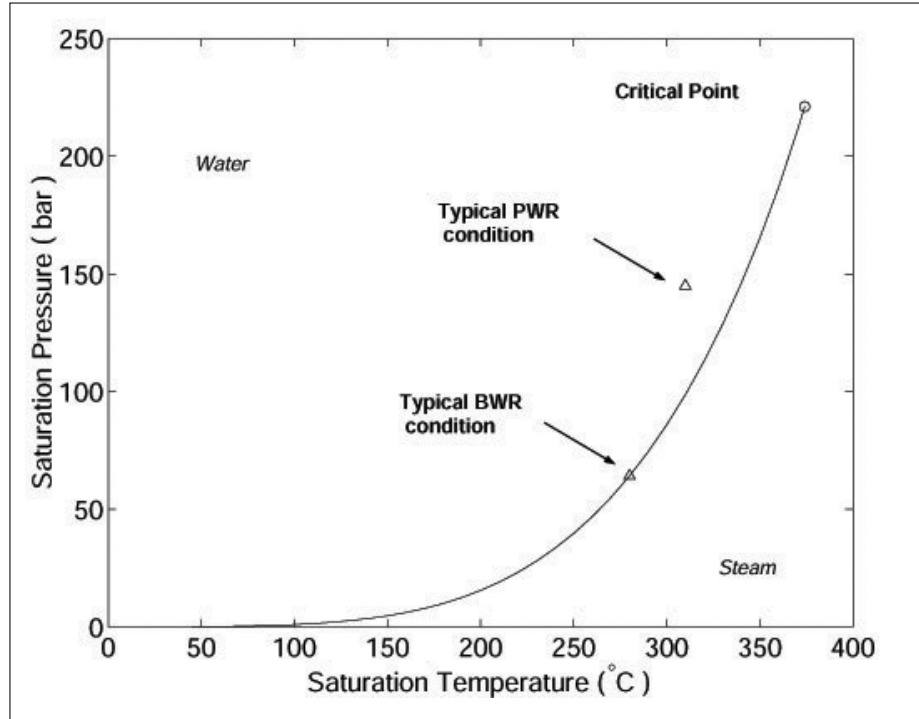

Fig. 5. Variation of the saturation pressure of water with temperature. Typical PWR and BWR primary system operating points are also shown.

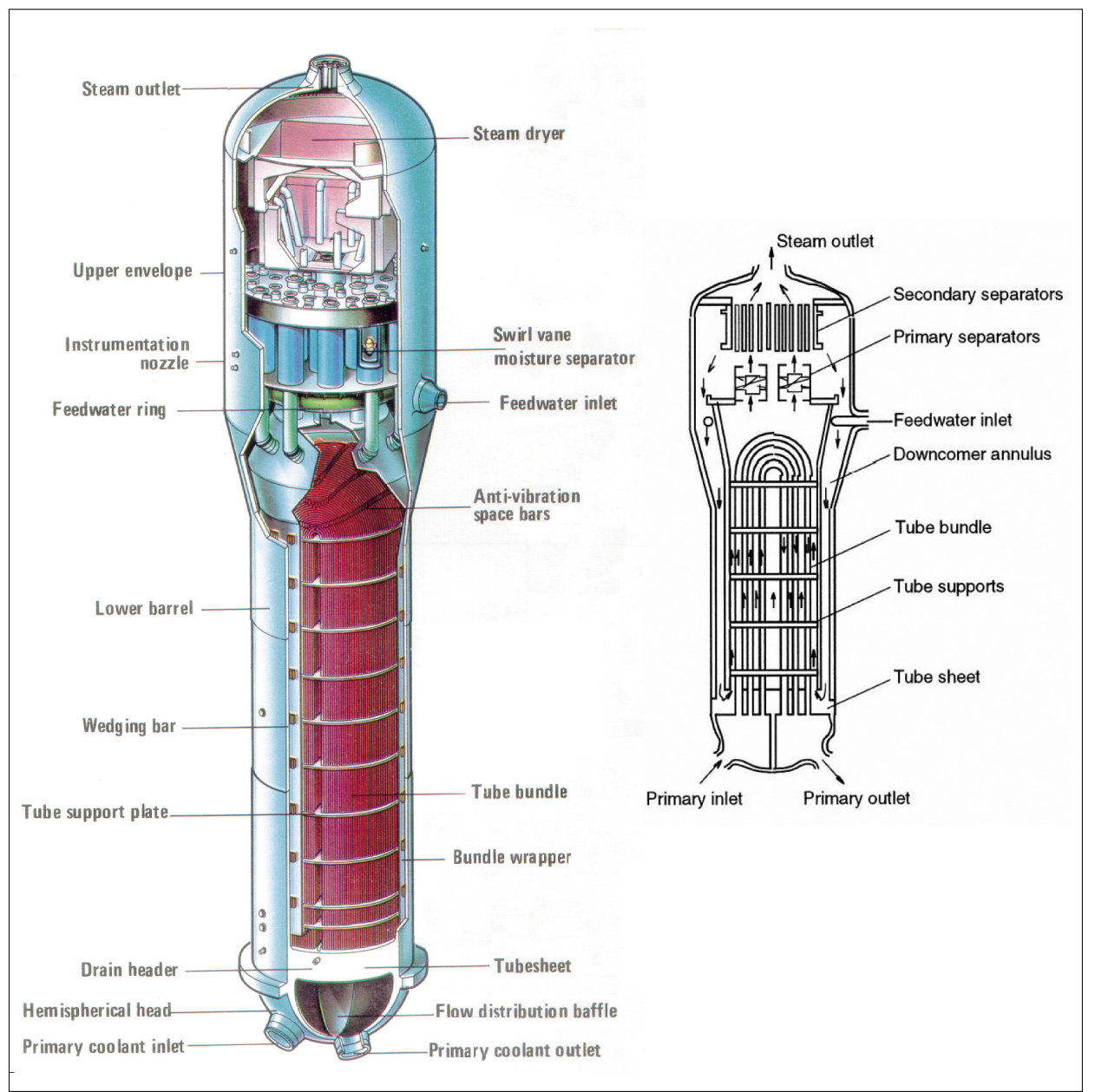

Fig. 6. PWR steam generator. Cut-out view on the left and schematic on the right.

typical U-tube steam generator producing saturated steam, used in the large majority of PWRs and Tables 4 and 5 give main design values. The maximum moisture at the outlet of the steam generator is typically $0.25 \%$.

The tubes of many of the SGs of early PWR plants suffered from severe materials and chemistry problems such as denting (reduction of the tube diameter when a magnetite corrosion product forms in the annulus between the carbon steel tube and the tube support plate or tubesheet), intergranular cracking attack at points of high stress concentration such as the smallest radius of the $U$ bend, wastage or thinning of the tube wall (that occurs when phosphate concentrates in the sludge on the tubesheet - sludge thicknesses of the order of $30 \mathrm{~cm}$ have been found), pitting (that occurs when aggressive chemicals such as chlorides concentrate on tube surfaces) and mechanical problems like vibration of the tubes which cause wear and fatigue. The easy remedy is to plug the damaged tubes; replacement of the SG is unavoidable, however, when too many tubes get plugged. Many PWR plants have already undergone SG replacement successfully.

\subsection{Light-Water as Coolant and Moderator}

Light water is a desirable coolant and moderator for several reasons; its advantages, as well as certain disadvantages are briefly discussed in this section.

\subsubsection{Pressure-Temperature Relationship}

In LWRs, the coolant, directly (the case of BWRs), or indirectly (the case of PWRs) constitutes also the working fluid for the thermodynamic steam cycle that produces the power. To increase the thermodynamic efficiency of the steam cycle, one wishes to operate at a temperature as high as possible. Since water boils, however, at relatively low temperature (compared, for example to the liquid metals), one must keep it under pressure to achieve higher temperatures. As Fig. 5 shows, the saturation pressure increases rapidly with relatively small increases of the saturation temperature as we approach the critical point. As increases in pressure solicit the components severely, a compromise must be reached between thermodynamic efficiency and structural (mechanical stress) considerations. For these reasons, the coolant temperatures remain relatively modest in LWRs, around $300{ }^{\circ} \mathrm{C}$, as we have seen above. Applying lower temperatures in the primary system has, however, also the advantage of allowing use of less expensive materials that do not have to withstand higher temperature environments. Thus, thermodynamic efficiency is again sacrificed to reduce capital costs. 
Table 4. Typical SG data for a four-loop French plant

\begin{tabular}{lll} 
& Primary circuit & Secondary circuit \\
\hline Gross electrical output per SG [MWe] & & 1347 / 4 \\
Maximal heat output per SG [MWth] & 4117 / 4 \\
Pressure [bar] & 155 & 72 \\
Temperatures $\left[{ }^{\circ} \mathrm{C}\right]$ & $328-293$ (inlet-exit SG) & 287.5 (steam) \\
Flow rate per SG $[\mathrm{kg} / \mathrm{s}]$ & 4593 & 539
\end{tabular}

Table 5. SG mechanical characteristics

\begin{tabular}{|c|c|c|c|c|}
\hline Plant & $\begin{array}{l}\text { Sizewell-B } \\
\text { (UK) }\end{array}$ & $\begin{array}{l}\text { Nogent } \\
\text { (France) }\end{array}$ & $\begin{array}{l}\text { Gösgen } \\
\text { (CH) }\end{array}$ & $\begin{array}{l}\text { Westing- } \\
\text { house plant } \\
\text { (USA) }\end{array}$ \\
\hline SG rated power [MWth] & 853 & 954 & 750 & \\
\hline SG tube outside diameter [mm] & 17.5 & & 22 & 22 \\
\hline SG tube thickness [mm] & 1 & & 1.2 & 1.27 \\
\hline Tube material & Inconel 600 & Inconel & Incoloy 800 & $\begin{array}{l}\text { Mo-Cr-Ni } \\
\text { steel clad } \\
\text { with inconel } \\
\text { on primary } \\
\text { face }\end{array}$ \\
\hline Number of SG tubes & 5600 & & & \\
\hline Total heat transfer area $\left[\mathrm{m}^{2}\right]$ & 5110 & & & \\
\hline Tubesheet thickness [mm] & 534 & & & \\
\hline Overall height [m] & 20.6 & 22.1 & & 20.6 \\
\hline Largest diameter [m] & 4.47 & 5.0 & & 4.50 \\
\hline Empty vessel mass [tonnes] & & 430 & 380 & 312 \\
\hline Mass at full-power operation [tonnes] & & 528 & & 377 \\
\hline Mass of vessel full of water [tonnes] & & 690 & & 510 \\
\hline
\end{tabular}

\subsubsection{Flashing of the Water}

The fact that water must always be used under pressure poses the main safety problem of LWRs. Indeed, if there is a break in the primary system envelope, the coolant 'flashes', i.e. produces steam due to the reduction of pressure, and escapes from the circuit. The energy stored in the coolant under pressure is considerable and is 'dumped' into the containment of the reactor, pressurizing it also. If the water present in the primary system is allowed to flash and come to equilibrium at the resulting final containment pressure, we find that little water is left in the vessel. Thus, emergency cooling water must be added to the RPV to assure cooling of the core. To assure reliability and redundancy, the emergency cooling systems of LWRs become complex. leads to very high centreline temperatures under normal operation (Fig. 7).

The fuel pins are arranged in bundles in a square lattice: $14 \times 14$ to $18 \times 18$ for PWRs and $7 \times 7$ to $10 \times 10$ for BWRs. The large PWRs contain typically some 200 bundles, while BWRs contain about 750 .

There are numerous material and chemistry considerations in the fuel assembly. As the fuel nuclei undergo fission, a diversity of chemical species appears in the fuel as fission products and the fuel becomes a complex mixture of chemical species. Some of the fission products may be solids, but others are volatile or gases and create voids in the somewhat porous structure of the fuel. As the fuel is subjected to thermal stresses, in particular during power level changes, it cracks; high temperatures promote, however, sintering of the cracks again. The differential pressure across the cladding, thermal expansion of the fuel, cracking, fuel swelling due to irradiation and cladding swelling combine to make the gap dimension variable during an irradiation cycle and the life of the fuel. The zirconium in the cladding reacts with high-temperature water, creates zirconium dioxide and releases hydrogen. The $\mathrm{ZrO}_{2}$ forms a thin film on the exposed surface of the cladding, while some of the hydrogen is picked up and remains in the cladding. These effects can clearly be influenced by the chemistry of the coolant [13].

The integrity of the cladding depends on several thermal-hydraulic and structural mechanics parameters such as the external coolant pressure; the internal fission-product gas pressure and the initial pressurization of the fuel rod, if any; swelling of fuel pellets due to irradiation; temperature gradients (steady-state and transient); thermal cycling (fatigue); creep; the mechanical deformation of the fuel bundle (fuel and supporting structure), etc. [14].

There is mechanical and chemical interaction between the fuel and the cladding; the so-called fuel-cladding interaction (FCI) is a concern addressed by specialists in this issue.

\subsection{Reactor Pressure Vessel and Core Internals}

The RPVs of LWRs are massive pieces of equipment with diameters of 4-7 m, heights of $10-20 \mathrm{~m}$ or more, and wall thicknesses of $0.2-0.3 \mathrm{~m}$. The vessels are made of ferritic steels, internally coated with stainless steel deposited by welding. Since the assumption of their failure is not a 'design-basis', they must be manufactured and monitored with extreme care. The vessels suffer damages from the flux of neutrons streaming from the core. Over the years of operation under irradiation, they become less ductile and their nilductility temperature is increased. Thus, they may fracture if subjected to thermal 


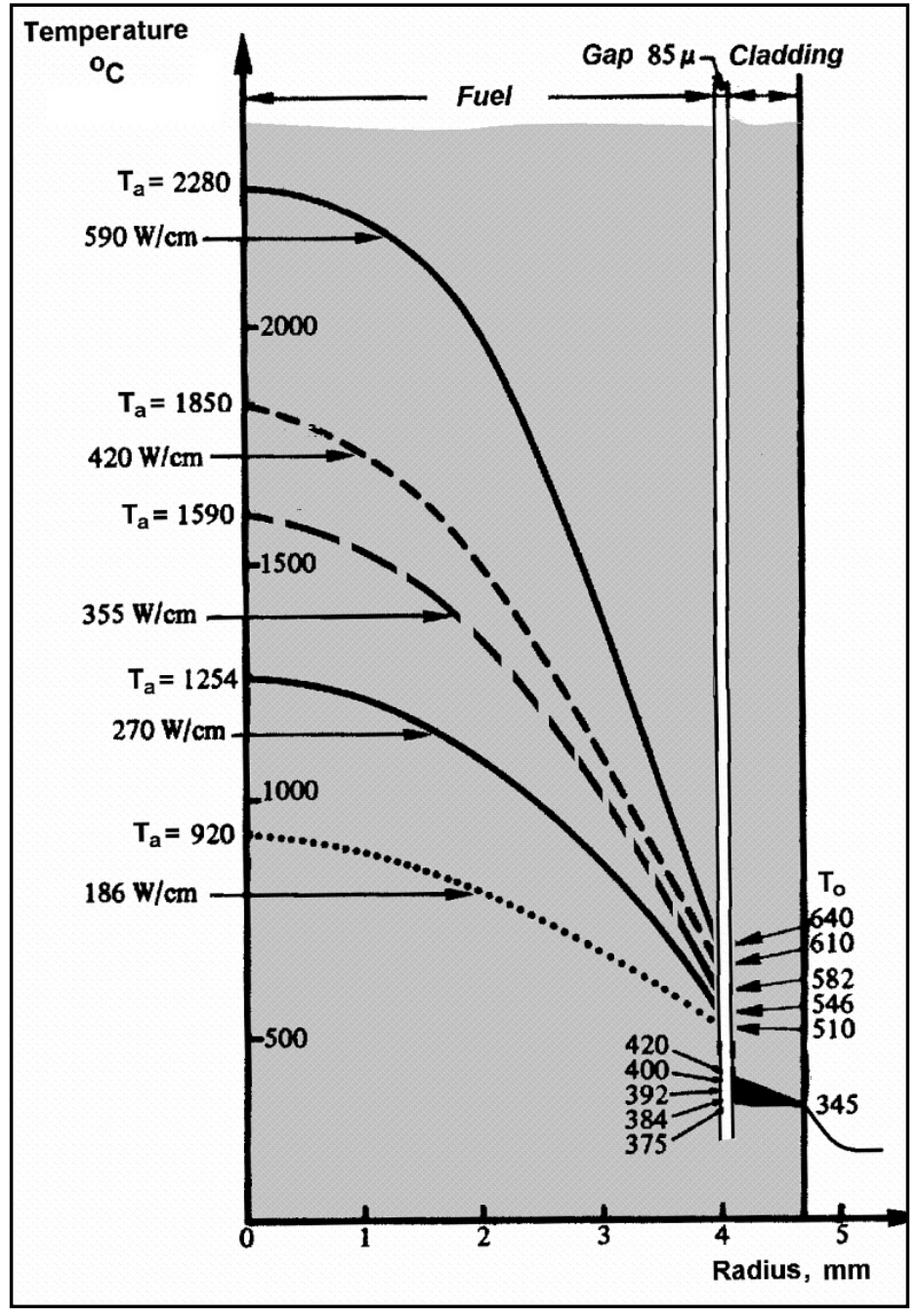

Fig. 7. Temperature distribution in a typical PWR fuel element at various linear power generation levels (adapted from [12]).

shocks, in the case, for example, of a Loss Of Coolant Accident (LOCA), in particular if this happens while they are still under pressure; this is the so-called Pressurized Thermal Shock (PTS) problem [15]. The PTS concern applies also to the large piping of the primary loops where cold emergency coolant is injected in hot pipes in case of a LOCA.

A number of materials problems, stress corrosion in particular, have also plagued the piping of LWRs, in particular, the large primary system pipes that have diameters of the order of $0.6 \mathrm{~m}$ and wall thicknesses of $\sim 60 \mathrm{~mm}$.

The integrity of core internals, i.e. the hardware inside the core, is also a concern; these are subjected to various stresses due to pressure and temperature gradients, vibrations, etc. and have occasionally suffered from cracking.

In summary, the combined effects of stresses, of the chemistry of the coolant, and of the metallurgical properties of the metals produce a number of concerns in relation to undesirable effects such as cracking, stress-induced corrosion, etc. These are the subject of specialized papers in this issue [16]

\subsection{Thermal Limits}

It is the physicochemical and metallurgical properties of materials that determine the performance limits of the reactor, in particular the thermal limits that the fuel and other core materials can sustain. In addition, the materials must withstand irradiation.

In designing the nuclear core, one tries to obtain

- high core power density ( $\mathrm{kW} / \mathrm{l}$ of core) to minimize core size;

- high fuel specific power $(\mathrm{kW} / \mathrm{kg}$ fuel) to minimize fuel inventory;

- high coolant exit temperature to maximize thermodynamic efficiency.

But the designer must ensure that

- design temperatures for the fuel and cladding materials remain below the melting temperatures or other metallurgically limiting temperatures;

- the values of the heat flux are below the critical heat flux (CHF) limit [17] so that the fuel rod temperatures remain low;
- the pressure drop across the core is minimized to limit pumping power requirements and hydraulic stresses on components.

One of the most important thermal limits that determines both the maximum fuel centreline temperature under normal operation, but also has a great influence on the cladding temperature under LOCA conditions will be discussed now.

\subsubsection{The Conductivity Integral}

The thermal conductivity of $\mathrm{UO}_{2}, \lambda_{f}$ varies significantly with temperature, and also depends on its density and on burnup. In spite of this, for cylindrical fuel elements, one obtains easily an implicit relationship between the linear heat generation rate $q$, (power produced per unit length of fuel rod in $\mathrm{kW} / \mathrm{m}$ ) and $\Delta T_{a o}$, the temperature drop in the fuel pellet, $T o-T a$ (Fig. 7):

$$
4 \pi \int_{T_{a}}^{T_{\mathrm{e}}} \lambda_{f} d T=q^{\prime}
$$

This equation is extremely useful, since it relates the average value of the thermal conductivity over the temperature interval across the fuel pellet - a fuel physical property - to $q^{\prime}$, a design parameter, and is independent of the rod diameter. Normally $T_{o}$ is set as the maximum allowable centreline temperature (a value somewhat below the fuel melting temperature or below a temperature at which, for example, metallic fuel may undergo some phase transformation). At the other end, $T_{a}$ is usually controlled by the mode of cooling and the coolant temperature. Indeed, the temperature drop between the surface of the fuel and the coolant is not large in LWRs (Fig. 7). Thus, for a given fuel and cooling-mode combination, the conductivity integral of the left side of the equation determines the maximum allowable value of the linear heat generation rate $q$ '. The melting point of the ceramic $\mathrm{UO}_{2}$ fuel used in LWRs is approximately $2860{ }^{\circ} \mathrm{C}$. For LWRs again, starting from a coolant temperature of roughly $300{ }^{\circ} \mathrm{C}$, and adding another few hundred degrees for temperature drops in the film (heat transfer between the coolant and the surface of the cladding), the cladding, and the gap between the cladding and the fuel, we obtain $T_{a}$ in the vicinity of 400 to $600{ }^{\circ} \mathrm{C}$ (Fig. 7). From the conductivity integral, we find that for LWR coolant conditions and $\mathrm{UO}_{2}$ fuel, the maximum allowable linear heat generation rate is limited to roughly

$$
q_{\text {max }}^{\prime}=60 \mathrm{~kW} / \mathrm{m}
$$

irrespective of the rod diameter. The optimal value of the rod diameter is determined by other considerations, such as neutronics (e.g. the water-to-fuel area ratio in the lat- 
tice), the economics of fabrication of fuel rods, the maximum allowable heat flux at the surface of the cladding, etc. In modern LWRs the maximum value of $q_{\text {max }}$ is kept well below the value of $60 \mathrm{~kW} / \mathrm{m}$ for other reasons: the fuel centreline temperature determines the thermal energy stored in the fuel; it is necessary to minimize this stored heat in order to limit the heatup of the cladding during the postulated LOCA. Indeed, if one insulates suddenly a fuel element and lets the heat stored in it to redistribute itself, the centreline temperature will be lowered, the fuel surface and cladding temperatures will rise, and the entire fuel element will take a temperature that, as can be easily shown, is equal to the arithmetic average of $T_{o}$ and $T_{a}$ (for this simple estimate we have ignored the presence of the cladding and its heat capacity). This value can be unacceptably high for the cladding [18].

The maximum value of $q$ ' will depend on the peaking factor, the ratio between the maximum of $q$ ' in the core to its average value. This peaking factor must be kept as low as possible to allow operation at higher average linear heat generation rate. In reality, $q^{\prime}{ }_{\text {max }}$ will change during the life of the core as the neutron flux distribution changes with burnup of the fuel. The technical safety specifications usually prescribe a maximum allowable value of $q^{\prime}{ }_{\max }$. The reactor operators must control the power density distribution in the core so that this value is never exceeded. If this value was to be exceeded, the total core power would have to be derated to bring $q^{\prime}$ max below the acceptable value again.

Older BWR bundles had $8 \times 8=64$ rods per bundle, while the PWR bundles had lattices of $14 \times 14$ rods. The tendency has been to increase the number of rods in the bundle, while keeping the same amount of fuel that gets distributed this way to a larger number of smaller rods. The newest fuel designs have $10 \times 10$ and $18 \times 18$ rods for BWRs and PWRs, respectively [19]. As a consequence, the peak value of the linear heat generation rate and the fuel centreline temperature are significantly lowered; this allows more flexibility in operations in relation to power peaking and permits higher power rating of the core.

\subsection{LWR Steam Cycles}

There is nothing particular to remark about PWR and BWR steam cycles; these are fairly conventional and rather 'old fashioned' since there is no superheat of the steam. As internal re-circulation systems like the SG of the PWR or the BWR primary system can produce only saturated steam, in the absence of any steam superheat, the steam at the exit of the high-pressure turbine will be wet. The water droplets that are produced at the exit of the high- pressure turbine must be mechanically separated from the steam, or the mixture is reheated, to avoid damages to the low-pressure turbine blades. Although the number of components and the particular arrangements may be different, the basic thermodynamic cycles are very similar. More information on the steam cycles can be found in [9] and [10].

Clearly, the conditions under which a LWR power generation cycle operates are well below those of modern fossil plants or high-temperature reactors. This is reflected in the relatively low thermodynamic efficiency of the LWR power cycles, which is $\sim 30-33 \%$ only. In fact there is no great economic incentive to increase the thermodynamic efficiency of those cycles by (necessarily) adding more equipment to the steam plant, since the costs of nuclear fuel are relatively low in comparison to those of fossil fuels. Thus, one saves on capital equipment at the expense of a lower thermodynamic efficiency.

The BWR direct cycle has the advantage of simplicity. The steam reaching the turbine, however, is radioactive due to neutron capture by the oxygen in the water:

${ }_{8} \mathrm{O}^{16}+{ }_{0} \mathrm{n}^{1} \rightarrow{ }_{7} \mathrm{~N}^{16}+{ }_{1} \mathrm{H}^{1}$

Nitrogen-16 is a beta and gamma emitter with a half-life of $7.2 \mathrm{~s}$. Thus, the radioactivity of the steam is short lived [10]. The steam may also, however, contain radioactive activation products due to impurities in the water, if its purity is not sufficiently high or if the primary circuit materials are not properly chosen to avoid excessive activation and the coolant chemistry is not correctly adjusted. The steam in the secondary circuit of PWRs has normally no radioactive contamination, except in case of steam generator tube leakages [9].

\section{Received: September 8, 2005}

[1] M. Gavrilas, P. Hejzlar, N.E. Todreas, Y. Shatilla, 'Safety Features of Operating Light Water Reactors of Western Design', Department of Nuclear Engineering, MIT, Cambridge, MA, 2000.

[2] W. Jeschki, H. Maxeiner, A. Nordström, M. Schweingruber, B. Volmert 'Radioactivity Buildup During Fuel Irradiation in Light Water Reactors (LWR)' Chimia 2005, 59, 916.

[3] S. Guentay, R.C. Cripps, B. Jäckel, H. Bruchertseifer, 'Iodine Behaviour during a Severe Accident in a Nuclear Power Plant', Chimia 2005, 59, 957.

[4] A.V. Nero, 'A Guidebook to Nuclear Reactors', University of California Press, Berkeley, 1979.

[5] 'World Nuclear Industry Handbook', annual compilation of the characteristics of all existing or projected power reactors in Nuclear Engineering International.

[6] P. Deramaix, 'Fuel Production for LWRs - MOX Fuel Aspects', Chimia 2005, 59, 905.

[7] G. Yadigaroglu, 'Passive Core and Containment Cooling Systems: Characteristics and State of the Art', Keynote Lecture, CD-ROM of Proc. Ninth International Topical Meeting on Nuclear Reactor Thermal Hydraulics (NURETH-9), San Francisco, California, October 3-8, 1999, American Nuclear Society.

[8] [GIF] 'A Technology Roadmap for Generation IV Nuclear Energy Systems', US DOE Nuclear Energy Research Advisory Committee and the Generation IV International Forum report GIF-002-00 (December 2002).

[9] M. Lips, 'PWR Water Chemistry - A Gösgen - Specific Overview', Chimia 2005, 59, 929.

[10] F.A. Sarott, 'Water Chemistry in Boiling Water Reactors - A Leibstadt - Specific Overview', Chimia 2005, 59, 923.

[11] D.R. Olander, 'Fundamental Aspects of Nuclear Reactor Fuel Elements', Technical Information Service, Energy Research and Development Administration, 1976.

[12] Collection CEA, 'Les réacteurs nucléaires à eau ordinaire', Eyrolles, Paris, 1983.

[13] G. Bart, J. Bertsch, 'Zirconium Alloys for Fuel Element Structures', Chimia 2005, 59, 938.

[14] H. Wiesenack, 'Review of Halden Reactor Project High Burnup Fuel Data that Can be Used in Safety Analyses', Nuclear Engineering and Design 1997, p. 83-92.

[15] S.T. Rosinski, R.O. Hardies, 'Pressurized Thermal Shock Screening Criteria ReEvaluation Effort-US Industry Activities', International Journal of Pressure Vessels and Piping 2001, p. 147-153.

[16] H.-P. Seifert, S. Ritter, 'The Role of Water Chemistry for Environmentally-Assisted Cracking in Low-Alloy Reactor Pressure Vessel and Piping Steels under Boiling Water Reactors Conditions', Chimia 2005, 59, 944.

[17] CHF: Water is an excellent heat transfer medium and can take up large heat loads. If, however, a certain value of the heat flux is exceeded, then heat transfer becomes suddenly very poor and the heat transfer surface may overheat; this is the "critical heat flux' phenomenon.

[18] M.A. Zimmermann, 'Review of the Licensing Basis for RIA and LOCA Transients in Light of New Evidence on High Burnup Fuel Behavior', Chimia 2005, 59, 950.

[19] 'Fuel Design Data', annual review in $\mathrm{Nu}$ clear Engineering International. 